\title{
Herbicidas alternativos para o controle de Raphanus raphanistrum L. resistente ao herbicida metsulfurom metílico ${ }^{1}$
}

\section{Alternative herbicides to control Raphanus raphanistrum L. resistant to metsulfuron methyl herbicide}

\author{
Leandro Oliveira da Costa ${ }^{2}$; Mauro Antônio Rizzardi ${ }^{3}$
}

\begin{abstract}
Resumo - O controle de plantas daninhas dicotiledôneas, em culturas de inverno, é realizado basicamente com herbicidas inibidores da enzima ALS. O uso intensivo desses herbicidas em áreas cultivadas com trigo tem proporcionado pressão de seleção nas populações de Raphanus raphanistrum resultando em biótipos resistentes a esses herbicidas. Objetivou-se com esse trabalho determinar a existência de resistência cruzada e múltipla aos herbicidas inibidores de ALS e alternativas de controle químico dessa planta daninha resistente ao metsulfurom metílico. Os tratamentos resultaram da combinação de dois biótipos de $R$. raphanistrum resistente (biótipo R) e suscetível (biótipo S), com 12 herbicidas: glifosato, atrazina, bentazona, 2,4-D, sulfometurom metílico + clorimurom etílico, clorimurom etílico, cloransulam metílico, iodosulfurom, nicossulfurom, imazetapir, metsulfurom metílico, imazapic + imazapir e mais um tratamento controle sem aplicação. Aplicou-se a dose recomendada de cada herbicida, para o controle da espécie, no estádio de desenvolvimento de 3 a 4 folhas verdadeiras. Foram analisados a eficiência de controle e redução de massa seca da parte aérea. $O$ biótipo $S$ foi suscetível aos herbicidas inibidores da ALS e aos demais mecanismos de ação testados. O biótipo R apresentou resistência cruzada aos grupos químicos imidazolinonas, sulfoniluréias e triazolpirimidinas variando o grau de sensibilidade entre esses grupos. O biótipo $\mathrm{R}$ não foi diagnosticado com resistência múltipla, e os herbicidas glifosato, bentazona, atrazina e 2,4-D demonstraram serem eficazes no seu controle, podendo utilizá-los como alternativas para o manejo químico dessa planta daninha.
\end{abstract}

Palavras-chaves: resistência cruzada, resistência múltipla, planta daninha, acetolactato sintase

Abstract - The control of weeds in winter crops is done primarily with ALS-inhibitor herbicides. The intensive herbicide use in areas with wheat has provided selection pressure on $R$. raphanistrum resulting in biotypes resistant to these herbicides. The objective of this work was to determine the existence of cross and multiple resistance to ALS-inhibitors herbicides and alternatives to chemical control of this weed resistant to metsulfuron methyl. Treatments consisted of $R$. raphanistrum resistant (biotype R) and susceptible (biotypes S), with 12 herbicides: glyphosate, atrazine, bentazone, 2,4-D, sulfometuron methyl + chlorimuron ethyl,

\footnotetext{
${ }^{1}$ Trabalho extraído de Dissertação do ppgAGRO-UPF. Recebido para publicação em 04/02/2014 e aceito em $01 / 04 / 2014$.

2 Eng. Agrônomo, Mestre, Doutorando em Agronomia da Universidade de Passo Fundo, PPGAgro-UPF. PassoFundo-RS. Email: leandro.jari@gmail.com

3 Eng. Agrônomo, Dr., Professor, ppgAgro-UPF, Pesquisador CNPq- Universidade de Passo Fundo, Faculdade de Agronomia e Medicina Veterinária da UPF, Caixa Postal 611, 99052-900 Passo Fundo-RS. E-mail: rizzardi@ upf.br
} 
chlorimuron ethyl, cloransulam methyl, iodosulfuron methyl, nicossulfuron, imazethapyr, metsulfuron methyl, imazapic + imazapyr and a control without herbicide. It was applied the recommended dose of each herbicide at 3 to 4 true leaves stage. Control efficiency and reduction in dry matter of shoots were analyzed. The biotype $S$ was susceptible to all herbicides used in the study. The biotype $\mathrm{R}$ has cross resistance to herbicides that belong to chemical group's imidazolinones, sulfonylureas and triazolopyrimidines varying degree of sensitivity between these groups. The biotype $\mathrm{R}$ was not diagnosed with multiple resistance and glyphosate, bentazone, atrazine and 2,4-D shown to be effective in controlling biotype $\mathrm{R}$ and can be used for chemical management of $R$. raphanistrum.

Keywords: cross resistance, multiple resistance, weed, acetolactate synthase

\section{Introdução}

A expressão do potencial produtivo das culturas atrela-se a fatores como intensidade, época e o grau de controle das plantas daninhas. O controle se faz necessário por que as plantas daninhas interferem com as culturas por fatores associados a expressão do potencial produtivo como água, luz e nutrientes (Ferri \& Vidal, 2003). Embora os herbicidas sejam ferramentas eficazes no manejo de plantas daninhas, a dependência excessiva em um único mecanismo de ação, propcia elevada pressão de seleção de indivíduos portadores de genes que conferem resistência a herbicidas (Nevill et al., 1998; Tranel \& Wright, 2002; Powles \& Preston, 2013).

No mundo, 131 espécies de plantas daninhas possuem resistência aos herbicidas inibidores da ALS, sendo os herbicidas com maior número de casos de resistência documentados. No Brasil já foram documentados 15 casos de resistência a esses herbicidas (Heap, 2013). A primeira espécie que evoluiu resistência aos herbicidas inibidores da ALS foi Bidens pilosa (Christoffoleti et al., 1996). Theisen (2008) documentou biótipos de Raphanus sativus L. com resistência cruzada aos herbicidas clorimurom etílico, cloransulam metílico, imazetapir, metsulfurom metílico e nicosulfurom. Recentemente, Costa (2013) comprovou a resistência de $R$. raphanistrum L. ao herbicida metsulfurom metílico.

Resistência cruzada ocorre quando biótipos de plantas daninhas são resistentes a dois ou mais herbicidas de diferentes grupos químicos com mesmo mecanismo de ação (Hall et al., 1994; Christoffoleti \& LópezOvejero, 2008).

A maioria dos estudos relata que biótipos resistentes aos herbicidas do grupo sulfoniluréia, dotados de mutação no local de ação do herbicida na enzima ALS, demonstra níveis variáveis de resistência cruzada para os grupos químicos imidazolinonas e triazolpirimidinas (Hall \& Devine, 1990; Saari et al., 1990; Saari et al., 1994; Walsh et al., 2004). Vargas et al. (1999) ao trabalhar com um biótipo de Euphorbia heterophylla resistente aos inibidores de ALS, relatou possuir resistência cruzada aos herbicidas imazaquim, imazetapir, imazamox, flumetsulam, exceto ao imazapir.

Yu et al. (2003) ao estudarem a base bioquímica e molecular de oito populações de $R$. raphanistrum resistentes aos herbicidas inibidores de ALS, provenientes de locais separados por distâncias consideráveis, verificaram que em todas as populações, a resistência é devido a uma enzima ALS insensível, e que todas possuem um padrão de resistência cruzada similar.

A base molecular da resistência aos herbicidas inibidores da ALS foi investigada e, identificada como sendo devido a mutação da alanina por tirosina no aminoácido 122 do gene da ALS (Han et al., 2012). Conforme os autores, essa mutação confere resistência de elevado grau e amplo espectro a herbicidas inibidores da ALS. 
A resistência múltipla ocorre quando o biótipo possui um ou mais mecanismos de resistência distintos conferindo resistência a herbicidas pertencentes a grupos químicos com dois ou mais mecanismos de ação (Christoffoleti \& López-Ovejero, 2008). Nesse sentido, populações $R$. Raphanistrum, no oeste da Austrália evoluíram resistência multipla a quatro mecanismos de ação herbicida (Walsh et al., 2006), ou seja: resistência aos inibidores de ALS (Walsh et al., 2001), inibidores de fotossistema II (Hashem et al., 2001; Walsh et al., 2004), mimetizadores de auxinas e inibidores da síntese de carotenóides (Walsh et al., 2004).

O uso de herbicidas alternativos, pertencentes a outros mecanismo de ação, é uma solução a curto prazo, mas que deverá ser integrado com outras formas de manejo como rotação de culturas, cultivares mais competitivas, densidade populacional adequada para cada cultura, sementes certificadas, cobertura de solo, entre outros (Nevill et al., 1998).

No Sul do Brasil, em lavouras cultivadas no período de inverno, principalmente na cultura do trigo, tem-se observado aumento de reclamações por parte de produtores em relação a infestações de $R$. raphanistrum não controlados pelos herbicidas inibidores de ALS, levando inclusive, desistência da semeadura de trigo em áreas infestadas com essa planta daninha. Com isso, levantou-se a hipótese de que haja resistência cruzada a esses herbicidas. Dessa forma, objetivou-se com esse trabalho, verificar a existência de resistência cruzada aos herbicidas inibidores de ALS ou resistência multipla a outros mecanismo de ação e, indicar alternativas para controle de $R$. raphanistrum resistente ao herbicida metsulfurom metílico.

\section{Material e Métodos}

Sementes de $R$. raphanistrum L. com suspeita de resistência aos herbicidas inibidores de ALS, oriundas de áreas onde ocorreram falhas de controle, no norte de Paraná, foram semeadas em vasos, em Passo Fundo, RS, e, quando atingiram 3 a 4 folhas verdadeiras, realizou-se pré-seleção de biótipos resistentes, com aplicação de 2,4 g i.a. ha ${ }^{-1}$ de metsulfurom metílico. As plantas que sobreviveram ao tratamento herbicida foram conduzidas até o final do ciclo para obtenção de sementes, constituindo assim a população suspeita de resistência (Biótipo R). A população suscetível (Biótipo $\mathrm{S}$ ) originou-se de sementes de $R$. raphanistrum existentes na área experimental da Universidade de Passo Fundo, onde não havia histórico de aplicação de herbicidas inibidores de ALS.

O experimento foi desenvolvido em casa de vegetação. As unidades experimentais consistiram de vasos plásticos de $17 \mathrm{~cm}$ de diâmetro e $14 \mathrm{~cm}$ de altura, com capacidade volumétrica de 2,5 L, perfazendo área superficial de $0,0453 \mathrm{~m}^{-2}$, preenchidos com substrato comercial do tipo Turfa Fértil ${ }^{\circledR}$. As sementes dos biótipos resistente e suscetível foram semeadas e mantidas em casa de vegetação. Após 15 dias da semeadura, realizou-se o desbaste, mantendo seis plantas de $R$. Raphanistrum por vaso. No estádio de desenvolvimento de três a quatro folhas verdadeiras, realizou-se a aplicação dos herbicidas com pulverizador costal de precisão pressurizado a $\mathrm{CO}_{2}$, utilizando pontas jato plano XR 110.02 , na altura de $50 \mathrm{~cm}$ acima do alvo, com pressão de trabalho a $2 \mathrm{kgf} \mathrm{cm}^{2} \mathrm{e}$ volume de aplicação de $200 \mathrm{~L} \mathrm{ha}^{-1}$.

Os tratamentos resultaram da combinação de dois biótipos de $R$. raphanistrum (biótipo $\mathrm{R}$ e biótipo $\mathrm{S}$ ), 12 herbicidas e um tratamento controle sem aplicação, que foram arranjados em fatorial $2 \mathrm{x}$ 13, completamente casualizado, com quatro repetições. O fator $\mathrm{A}$ foi constituído pelos biótipos $\mathrm{R}$ e biótipo $\mathrm{S}$, e $\mathrm{o}$ fator $\mathrm{B}$ pelos herbicidas e suas respectivas doses comerciais. Os herbicidas utilizados e, respectivas doses, foram: metsulfurom metílico $\left(2,4 \mathrm{~g}\right.$ i.a. $\left.\mathrm{ha}^{-1}\right)$, imazapic + imazapir $\left(2,6+7,9\right.$ g i.a. ha $\left.{ }^{-1}\right)$, 
iodosulfurom metílico (5 g i.a. $\left.\mathrm{ha}^{-1}\right)$, clorimurom etílico (20 g i.a. ha $\left.{ }^{-1}\right)$, imazetapir $\left(100 \mathrm{~g}\right.$ i.a. ha $\left.{ }^{-1}\right)$, sulfometurom metílico + clorimurom etílico $\left(75+25 \mathrm{~g}\right.$ i.a. ha $\left.{ }^{-1}\right)$, nicossulfurom (22,5 g i.a. ha $\left.{ }^{-1}\right)$, cloransulam metílico (30 g i.a. ha ${ }^{-1}$ ), 2,4-D (1209 g e.a. ha ${ }^{1}$ ), bentazona (720 g i.a. ha $\left.{ }^{-1}\right)$, glifosato (960 g e.a. ha $\left.{ }^{-1}\right)$ e atrazina $\left(2500 \mathrm{~g}\right.$ i.a. ha $\left.{ }^{-1}\right)$. Para todos os herbicidas utilizou-se o adjuvante Lanzar $^{\circledR}$, na dose de $0,5 \%$ do volume de calda, exceto para o glifosato.

Avaliou-se, visualmente, o controle dos biótipos aos 14 e 35 dias após aplicação (DAA) dos herbicidas. Para o controle utilizou-se como base a escala percentual, em que a nota $0 \%$ correspondeu a nenhum efeito do herbicida e a nota $100 \%$ significou morte completa das plantas. Avaliações de massa seca (MS) foram realizadas retirando-se três plantas por vaso aos 14 DAA e 35 DAA. Posteriormente, estas plantas foram secas em estufa a $65^{\circ} \mathrm{C}$ por 72 horas, até peso constante para a quantificação de MS.

Os valores de MS foram transformados para percentuais, partindo-se do princípio de que as parcelas que permaneceram sem aplicação de herbicida possuem 100\% de MS e as demais possuem percentuais desta biomassa, em consequência da redução imposta pelos herbicidas (Beckie et al., 2012). Os dados relativos ao percentual de controle e de MS foram normalizados pela transformação em raiz quadrada de $(x+1)$, para realização da análise de variância.

Os dados foram submetidos à análise de variância e testados pelo teste $\mathrm{F}$, e quando significativos $(\mathrm{P}<0,05)$, procedeu-se à análise comparativa pelo teste de Tukey a $5 \%$ de probabilidade de erro.

\section{Resultados e Discussão}

A análise de variância foi significativa para todas as variáveis analisadas, com interação significativa dos fatores biótipos de $R$. raphanistrum e herbicidas para controle e
MS, aos 14 e 35 DAA. O efeito de controle dos herbicidas variou de acordo com o biótipo avaliado (Tabela 1). Aos 14 DAA, todos os herbicidas exerceram eficiência de controle acima de $90 \%$ no biótipo $\mathrm{S}$, com destaque para o glifosato que atingiu 98\%. Já para o biótipo $\mathrm{R}$, os herbicidas inibidores de ALS mostraramse ineficientes, sendo que, o inibidor de ALS a atingir maior eficiência de controle foi $\mathrm{o}$ clorimurom + sulfometurom, com $28 \%$. Os herbicidas glifosato, atrazina, bentazona e 2,4D controlaram 98, 94, 93 e 92\%, respectivamente, não diferenciando significativamente o nível de controle entre os biótipos $\mathrm{R}$ e $\mathrm{S}$.

Mesmo esses herbicidas terem controlado satisfatoriamente biótipos $\mathrm{R}$ e $\mathrm{S}$, é de extrema importância não depender de poucos ou exclusivamente de um herbicida para realizar o manejo de $R$. raphanistrum (Hashem et al., 2001), principalmente em áreas de cereais de inverno, pois pode ocorrer rapidamente a evolução da resistência para herbicidas de outros mecanismos de ação (Walsh et al., 2006). Imazapic + imazapir não demonstrou nenhuma ação herbicida sobre o biótipo $\mathrm{R}$, não se diferenciando da testemunha sem herbicida, seguido de metsulfurom e imazetapir.

Aos 35 DAA, todos os herbicidas exerceram $100 \%$ de controle no biótipo $\mathrm{S}$, enquanto que, no biótipo $\mathrm{R}$ apenas os herbicidas de mecanismo de ação diferente da ALS, controlaram $100 \%$ (Tabela 1). Os herbicidas inibidores de ALS possuem como características a eficácia elevada, em doses comerciais, sobre biótipos sensíveis (Tranel \& Wright, 2002). Entre os herbicidas inibidores de ALS, o cloransulam foi o que mais obteve êxito no controle do biótipo R com $54 \%$. Nos demais, o controle foi inferior, com destaque ao imazapic + imazapir, metsulfurom e imazetapir que não proporcionaram nenhum efeito de controle. 
Tabela 1. Controle (\%) de Raphanus raphanistrum resistente (biótipo R) e suscetível (biótipo S) ao herbicida metsulfurom metílico, 14 e 35 dias após aplicação (DAA). Passo Fundo- RS, 2012.

\begin{tabular}{|c|c|c|c|c|c|}
\hline \multirow{3}{*}{ Herbicidas } & \multirow{3}{*}{$\begin{array}{c}\text { Dose } \\
\left(\mathrm{g} \mathrm{ha}^{-1}\right) \\
\text { (i.a ou e.a.) }\end{array}$} & \multicolumn{2}{|c|}{14 DAA } & \multicolumn{2}{|c|}{35 DAA } \\
\hline & & Biótipo R & Biótipo S & Biótipo R & Biótipo $\mathrm{S}$ \\
\hline & & \multicolumn{4}{|c|}{ 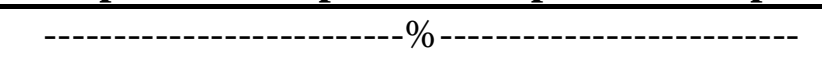 } \\
\hline Glifosato & 960 & A $98 a^{1 /}$ & A $98 \mathrm{a}$ & A 100 a & A $100 \mathrm{a}$ \\
\hline Atrazina & 2500 & A 94 a & A 95 a & A $100 \mathrm{a}$ & A 100 a \\
\hline Bentazona & 720 & A 93 a & A 94 a & A $100 \mathrm{a}$ & A $100 \mathrm{a}$ \\
\hline 2,4-D & 1209 & A 92 a & A 95 a & A $100 \mathrm{a}$ & A $100 \mathrm{a}$ \\
\hline Clorimurom+ Sulfometurom & $25+75$ & B $28 \mathrm{~b}$ & A 94 a & B $30 \mathrm{~d}$ & A 100 a \\
\hline Clorimurom & 20 & B $22 \mathrm{c}$ & A 95 a & B $43 \mathrm{c}$ & A 100 a \\
\hline Cloransulam & 30 & B $22 \mathrm{c}$ & A 93 a & B $54 \mathrm{~b}$ & A $100 \mathrm{a}$ \\
\hline Iodosulfurom & 5 & B $16 \mathrm{~d}$ & A 92 a & B $18 \mathrm{f}$ & A 100 a \\
\hline Nicossulfuron & 22,5 & B $11 \mathrm{e}$ & A 94 a & B $24 \mathrm{e}$ & A $100 \mathrm{a}$ \\
\hline Imazetapir & 100 & B $2 \mathrm{f}$ & A 93 a & B $0 \mathrm{~g}$ & A 100 a \\
\hline Metsulfurom & 2,4 & B $1 \mathrm{f}$ & A 93 a & B $0 \mathrm{~g}$ & A $100 \mathrm{a}$ \\
\hline Imazapic+ Imazapir & $2,6+7,9$ & B $0 \mathrm{f}$ & A 94 a & B $0 \mathrm{~g}$ & A 100 a \\
\hline Sem herbicida & - & $\mathrm{A} 0 \mathrm{f}$ & $\mathrm{A} 0 \mathrm{~b}$ & $\mathrm{~A} 0 \mathrm{~g}$ & $\mathrm{~A} 0 \mathrm{~b}$ \\
\hline $\mathbf{F}_{\text {Biótipos }}$ & & \multicolumn{2}{|c|}{$18988,90 *$} & \multicolumn{2}{|c|}{$51279,10 *$} \\
\hline $\mathbf{F}_{\text {Tratamentos }}$ & & \multicolumn{2}{|c|}{$2336,02 *$} & \multicolumn{2}{|c|}{$7817,72 *$} \\
\hline C.V. $(\%)$ & & \multicolumn{2}{|c|}{2,04} & \multicolumn{2}{|c|}{1,12} \\
\hline $\mathbf{D M S}_{\text {Biótipos }}$ & & \multicolumn{2}{|c|}{0,205} & \multicolumn{2}{|c|}{0,118} \\
\hline DMS $_{\text {Tratamentos }}$ & & \multicolumn{2}{|c|}{0,351} & \multicolumn{2}{|c|}{0,203} \\
\hline
\end{tabular}

II Médias seguidas pela mesma letra minúscula, na coluna, ou maiúscula na linha comparadas na mesma data de avaliação, não diferem entre si pelo teste de Tukey a 5\% de probabilidade de erro. ${ }^{*} \mathrm{p} \leq 0,05$; Dados transformados $\operatorname{para} \sqrt{(x+1)}$.

Yu et al. (2012) avaliaram população homozigota de $R$. raphanistrum resistente aos herbicidas inibidores de ALS, quando submetida a aplicação de chlorsulfuron, imazamox e metosulam, nas doses de: 5 e 10; 12,5 e $25 ; 3$ e 6 g i.a. ha $^{-1}$ respectivamente, não obtiveram controle, contudo, para o biótipo suscetível as doses menores controlaram $100 \%$ aos 21 dias após o tratamento.

Através dos resultados de controle é possível afirmar que glifosato, atrazina, bentazona e 2,4-D são eficazes no controle do biótipo $\mathrm{R}$, e que podem fazer parte de uma rotação de herbicidas de diferentes mecanismos de ação. Também ficou evidenciado que a população do biótipo $\mathrm{R}$ possui resistência cruzada aos grupos químicos das imidazolinonas, sulfoniluréias triazolpirimidinas (Figura 1). Costa (2013) observou níveis elevados de resistência de $R$. raphanistrum, oriundos desses mesmos biótipos, ao metsulfurom metílico chegando ao fator de resistência $(\mathrm{F})$ 85. O fator $\mathrm{F}(\mathrm{F}=\mathrm{R} / \mathrm{S})$ expressa o número de vezes em que a dose necessária para controlar $50 \%$ do biótipo resistente é superior à dose que controla $50 \%$ do biótipo suscetível (Hall et al., 1998).

Christoffoleti (2002) e Vargas et al. (1999) observaram que biótipos de Bidens pilosa e E. heterophylla demonstraram níveis altos de resistência cruzada às sulfoniluréias e imidazolinonas. 


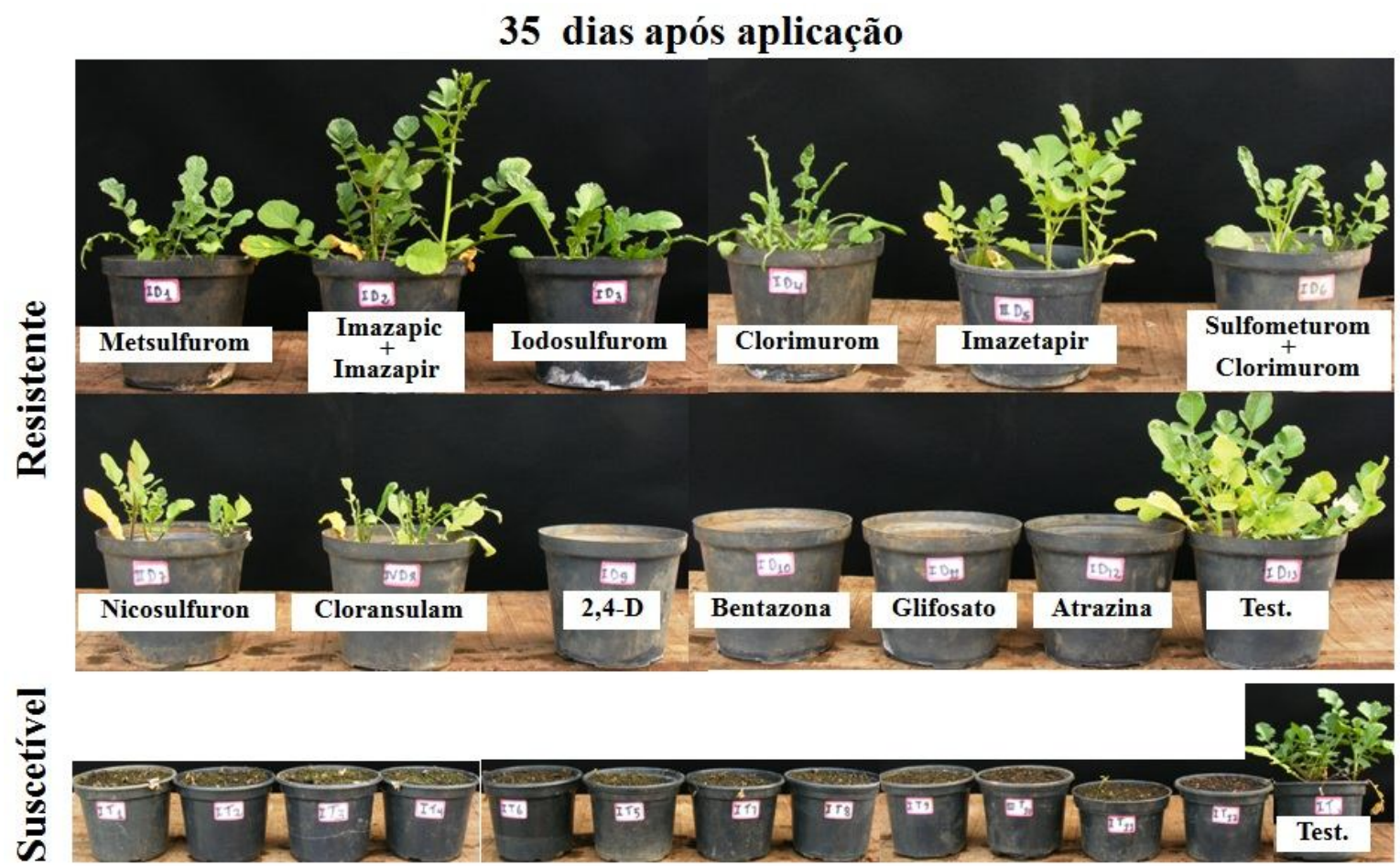

Figura 1. Controle de biótipos de Raphanus raphanistrum resistente e suscetível aos 35 dias após aplicação dos herbicidas (Test.= Testemunha sem herbicida). FAMV-UPF, Passo Fundo, RS, 2012.

A MS variou entre os biótipos $\mathrm{R}$ e $\mathrm{S}$ como resultado da aplicação dos herbicidas. Para o biótipo $\mathrm{R}$, a porcentagem de MS foi diferente entre os herbicidas inibidores da ALS e os pertencentes a outros mecanismos de ação (Tabela 2).

Aos 14 DAA, a porcentagem de MS entre os biótipos $\mathrm{R}$ e $\mathrm{S}$ não diferiu entre os herbicidas bentazona, atrazina, 2,4-D e glifosato. O menor percentual de MS, para ambos os biótipos, foi em resposta à aplicação do glifosato. Este fato pode estar relacionado com a alta mobilidade do glifosato nos tecidos dos vegetais e melhor ação de controle que este herbicida exerce em plantas em estádio inicial de 3 a 4 folhas (Koger et al., 2004). O metsulfurom foi o que menos reduziu a MS do biótipo R, não diferindo dos herbicidas imazetapir e imazapic + imazapir. Entre os inibidores de ALS, o sulfometurom + clorimurom foi o que mais reduziu a MS do biótipo R, chegando ao valor de $27 \%$ de MS em relação à parcela não tratada.

Os resultados de MS aos 35 DAA (Tabela 2) foram semelhantes aos resultados de controle (Tabela 1). A MS do biótipo S reduziu a $0 \%$ em todos os tratamentos herbicidas, demonstrando que esse biótipo é facilmente controlado tanto por herbicidas inibidores de ALS quanto por de outros mecanismos de ação. Os herbicidas glifosato, bentazona, atrazina e 2,4-D reduziram $100 \%$ da MS do biótipo R. Entre os herbicidas inibidores de ALS, o biótipo $\mathrm{R}$ demonstrou níveis diferenciados de MS em resposta ao tratamento com esses herbicidas. O imazapic + imazapir, imazetapir e metsulfurom não diferiram da testemunha, sem herbicida, em relação a MS. Já o cloransulam foi o que exerceu maior efeito de redução de $\mathrm{MS}$ do biótipo $\mathrm{R}$ entre os inibidores de ALS. 
Tabela 2. Massa seca (\%) de Raphanus raphanistrum resistente (biótipo R) e suscetível (biótipo S) ao herbicida metsulfurom metílico, 14 e 35 dias após aplicação (DAA). Passo Fundo- RS, 2012.

\begin{tabular}{|c|c|c|c|c|c|}
\hline \multirow{3}{*}{ Herbicidas } & \multirow{3}{*}{$\begin{array}{c}\text { Dose } \\
\left(\mathrm{g} \mathrm{ha}^{-1}\right) \\
\text { (i.a ou e.a.) }\end{array}$} & \multicolumn{2}{|c|}{14 DAA } & \multicolumn{2}{|c|}{35 DAA } \\
\hline & & Biótipo R & Biótipo S & Biótipo $\mathbf{R}$ & Biótipo S \\
\hline & & \multicolumn{4}{|c|}{-----------------------------\%0------------------------- } \\
\hline Glifosato & 960 & A $11 \mathrm{a}^{\underline{1}}$ & A 14 a & A $0 \mathrm{a}$ & A $0 \mathrm{a}$ \\
\hline Bentazona & 720 & A 16 a & A $18 \mathrm{ab}$ & A $0 \mathrm{a}$ & A $0 \mathrm{a}$ \\
\hline Atrazina & 2500 & A $17 \mathrm{a}$ & A 17 a & A 0 a & A 0 a \\
\hline $2,4-\mathrm{D}$ & 1209 & A 18 a & A $19 \mathrm{ab}$ & A $0 \mathrm{a}$ & A $0 \mathrm{a}$ \\
\hline Clorimurom+ Sulfometurom & $25+75$ & A $27 \mathrm{~b}$ & B $34 \mathrm{~d}$ & B $54 \mathrm{c}$ & A $0 \mathrm{a}$ \\
\hline Cloransulam & 30 & B 56 c & A $31 \mathrm{~cd}$ & B 39 b & A 0 a \\
\hline Clorimurom & 20 & B $64 \mathrm{~cd}$ & A 33 a & B 54 c & A $0 \mathrm{a}$ \\
\hline Iodosulfurom & 5 & B 70 de & A $34 \mathrm{~d}$ & B $81 \mathrm{de}$ & A 0 a \\
\hline Nicossulfuron & 22,5 & B $75 \mathrm{e}$ & A $36 \mathrm{~d}$ & B $65 \mathrm{~cd}$ & A $0 \mathrm{a}$ \\
\hline Imazapic+ Imazapir & $2,6+7,9$ & B $98 \mathrm{f}$ & A $32 \mathrm{~cd}$ & B $97 \mathrm{ef}$ & A $0 \mathrm{a}$ \\
\hline Imazetapir & 100 & B $95 \mathrm{f}$ & A $32 \mathrm{~cd}$ & B 96 ef & A $0 \mathrm{a}$ \\
\hline Metsulfurom & 2,4 & B $98 \mathrm{f}$ & A 25 bc & B 96 ef & A $0 \mathrm{a}$ \\
\hline Sem herbicida & - & A $100 \mathrm{f}$ & A $100 \mathrm{e}$ & A $100 \mathrm{f}$ & A $100 \mathrm{~b}$ \\
\hline $\mathbf{F}_{\text {Biótipos }}$ & & \multicolumn{2}{|c|}{$1539,95 *$} & \multicolumn{2}{|c|}{$1774,81 *$} \\
\hline $\mathbf{F}_{\text {Tratamentos }}$ & & \multicolumn{2}{|c|}{$441,32 *$} & \multicolumn{2}{|c|}{$171,66 *$} \\
\hline C.V. $(\%)$ & & \multicolumn{2}{|c|}{0,80} & \multicolumn{2}{|c|}{3,50} \\
\hline $\mathbf{D M S}_{\text {Biótipos }}$ & & \multicolumn{2}{|c|}{0,013} & \multicolumn{2}{|c|}{0,061} \\
\hline DMS $_{\text {Tratamentos }}$ & & \multicolumn{2}{|c|}{0,022} & \multicolumn{2}{|c|}{0,104} \\
\hline
\end{tabular}

II Médias seguidas pela mesma letra minúscula, na coluna, ou maiúscula na linha comparadas na mesma data de avaliação, não diferem entre si pelo teste de Tukey a 5\% de probabilidade de erro. $* \mathrm{p} \leq 0,05 ;$ Dados transformados para $\sqrt{(x+1)}$.

Estudos realizados por Vidal \& Merotto Jr. (1999) com biótipo de E. heterophylla demonstraram que o mesmo possuía resistência cruzada aos herbicidas inibidores de ALS e não foi controlado com 8 vezes a dose comercial de imazetapir, mas foi suscetível aos herbicidas glifosato, 2,4-D, dicamba, paraquat, atrazina, fomesafen e lactofen. Já Vargas (2000) ao também testar biótipos de E. heterophylla, observou resistência cruzada aos herbicidas imazetapir e imazamox, mas suscetibilidade ao imazapir. Isso sugere que o biótipo de planta daninha ao ser resistente a um herbicida inibidor de ALS, não necessariamente terá resistência cruzada a todos os outros do mesmo grupo químico.

Dessa forma, embasado nos resultados de controle e MS, é correto afirmar que o biótipo $\mathrm{R}$ possui resistência cruzada a todos inibidores de ALS testados, e o grau de sensibilidade desse biótipo aos herbicidas foi diferenciando. Em estudos com Xanthium strumarium foram determinados os níveis de resistência cruzada de: 1,1 para clorimurom (sulfoniluréia), >324 para imazaquim (imidazolinona) e 1,4 para flumetsulam (triazolpirimidina) (Schmitzer et al., 1993). As variações no nível de resistência cruzada dentro dos inibidores de ALS possivelmente se devem à ligação diferenciada e particular de cada herbicida ao local de ação e diferentes mutações que ocorrem no gene que codifica a enzima ALS (Powles \& Preston, 2013).

$\mathrm{O}$ biótipo $\mathrm{R}$ não apresentou evolução para resistência múltipla aos herbicidas 2,4-D (mimetizador de auxinas), glifosato (inibidor 
de EPSPS), atrazina e bentazona (inibidores do fotossistema II). Esses herbicidas foram eficazes no controle do biótipo $\mathrm{R}$ e podem ser utilizados para o manejo químico dessa espécie resistente aos herbicidas inibidores da enzima ALS. Porém, mesmo sendo herbicidas que exercem controle eficaz e eficiente de populações resistentes, é necessário adotar diferentes estratégias a fim de evitar e prevenir a resistência generalizada de plantas daninhas a estes herbicidas.

\section{Conclusões}

O biótipo de $R$. raphanistrum, originário de Cafelândia/PR, possui apenas resistência cruzada aos herbicidas inibidores de ALS, não apresentando resistência múltipla a outro mecanismo de ação.

O biótipo de $R$. raphanistrum, resistente aos herbicidas inibidores de ALS, é suscetível aos herbicidas glifosato, bentazona, atrazina e 2,4-D, caracterizando-se como alternativos para o manejo de populações do biótipo resistente aos inibidores de ALS.

\section{Referências}

BECKIE, H.J.; WARWICK, S.I.; SAUDER, C. A. Acetolactate synthase (ALS) inhibitorresistant wild buckwheat (Polygonum convolvulus) in alberta. Weed Technology, v.26, n.1, p.156-160, 2012.

CHRISTOFFOLETI, P.J. Curvas de doseresposta de biótipos resistente e suscetível de Bidens pilosa L. aos herbicidas inibidores da ALS. Scientia Agrícola, v.59, n.3, p.513-519, 2002.

CHRISTOFFOLETI, P.J. et al. Imidazolinone resistant $B$. pilosa biotypes in the Brazilian soybean areas. In: 1996 MEETING OF THE WEED SCIENCE SOCIETY OF AMERICA, Norfolk, 1996. Abstract. Norfolk, 1996, v.36, p. 10 .

CHRISTOFFOLETI, P.J.; LÓPEZ-OVEJERO, R.F. Resistência das plantas daninhas a herbicidas: definições, bases e situação no Brasil e no mundo. In: CHRISTOFFOLETI, P.J. (Coord.) Aspectos de resistência de plantas daninhas a herbicidas. 3. ed., rev. e atual, Piracicaba: Associação Brasileira de Ação a resistência de Plantas aos Herbicidas (HRAC-BR), 2008, p. 9-34.

COSTA, L.O. Resistência de Raphanus raphanistrum $\mathrm{L}$. aos herbicidas inibidores da enzima acetolactato sintase (ALS/AHAS). 2013. 114 f. Dissertação (Mestrado em Agronomia)- Faculdade de Agronomia e Medicina Veterinária, Universidade de Passo Fundo, Passo Fundo, 2013.

FERRI, M.V.W.; VIDAL, R.A. Controle de plantas daninhas com herbicidas cloroacetamidas em sistemas convencional e de semeadura direta. Planta Daninha, v.21, n.1, p.131-136, 2003.

HALL, L.M.; DEVINE, M.D. Cross-resistance of a chlorsulfuron-resistant biotype of Stellaria media to a triazolopyrimidine herbicide. Plant Physiology, v.93, n.3, p.962-966, 1990.

HALL, L.M.; HOLTUM, J.A.M.; POWLES, S.B. Mechanisms responsible for cross resistance and multiple resistance. In POWLES, S.B.; HOLTUM, A.M. Herbicide Resistance in Plants: Biology and Biochemistry. Boca Raton, Lewis Publishers, 1994, p.243-261.

HAN, H. et al. A novel amino acid substitution Ala-122-Tyr in ALS confers high-level and broad resistance across ALS-inhibiting herbicides. Pest Management Science, v.68, n.8, p.1164-1170, 2012.

HASHEM, A. et al. Resistance of wild radish (Raphanus raphanistrum) to acetolactate synthase-inhibiting herbicides in the western Australia wheat belt weed. Weed Technology, v.15, n.1, p.68-74, 2001.

\section{HEAP, I. International Survey of Herbicide} resistant Weeds. Disponível em: 
http: <//www.weedscience.org/In.asp>. Acesso em: 05 jan. 2013.

KOGER, C.H.; POSTON, D.H.; REDDY, K.N. Effect of glyphosate spray coverage on control of pitted morningglory (Ipomoea lacunosa). Weed Technology, v.18, n.1, p.124-130, 2004.

NEVILL, D.; CORNES, D.; HOWARD, S. Weed resistance: The Role of $H R A C$ in the Management of Weed Resistance. Pesticide Outlook, 1998. Disponível em: < http://www.hracglobal.com/Publications/HRA CManagementandWeedResistance.aspx $>$.

Acesso em: 15 jan. 2013.

POWLES, S.B.; PRESTON, C. Herbicide cross resistance and multiple resistance in plants. Disponível em: http://www.hracglobal.com/Publications/Herbi cideCrossResistanceandMultipleResistance.asp X. Acesso em: 14 jan. 2013.

SAARI, L.L.; COTTERMAN, J.C.; PRIMIANI, M.M. Mechanism of sulfonylurea herbicide resistance in the broadleaf weed, Kochia scoparia. Plant Physiology, v.93, n.1, p.55-61, 1990.

SAARI, L.L.; COTTERMAN, J.C.; THILL, D.C. Resistance to acetolactate synthase inhibiting herbicides. In: POWLES, S.B.; HOLTUM, A.M. Herbicide Resistance in Plants: Biology and Biochemistry. Boca Raton, Lewis Publishers, 1994. p.83-139.

SCHMITZER, P.R.; EILERS, R.J.; CSÉKE, C. Lack of cross-resistance of imazaquin-resistant Xanthium strumarium acetolactate synthase to flumetsulam and chlorimuron. Plant Physiology, v.103, n.1, p.281-283, 1993.

THEISEN, G. Aspectos botânicos e relato a resistência de nabo silvestre aos herbicidas inibidores de ALS. Pelotas: Embrapa Clima Temperado, 2008, 26 p. (Documento 239).

TRANEL, P.J.; WRIGHT, T.R. Resistance off weeds to ALS-inhibiting herbicides: what have we learned? Review. Weed Science, v.50, n.6, p.700-712, 2002.

VARGAS, L. et al. Resistência de planta daninha a herbicidas. Ed. 1. Viçosa-MG: UFV, 1999. $131 \mathrm{p}$.

VARGAS, L. Resistência de Euphorbia heterophylla $\mathrm{L}$. aos herbicidas inibidores da enzima acetolactato sintase (ALS/AHAS). 2000. 58 f. Tese (Doutorado em Fitotecnia)Universidade Federal de Viçosa, Viçosa-MG, 2000 .

VIDAL, R.A.; MEROTTO JR, A. Resistência de amendoim-bravo aos herbicidas inibidores de ALS. Planta Daninha, v.17, n.3, p.367373, 1999.

WALSH, M.J. et al. Multiple-herbicide resistance across four modes of action in wild radish (Raphanus raphanistrum). Weed Science, v.52, n.1, p.8-13, 2004.

WALSH, M.J.; DUANE, R.D.; POWLES,S. B. High frequency of chlorsulfuron-resistant wild radish (Raphanus raphanistrum) populations across the western Australian wheat belt. Weed Technology, v.15, n.2, p.199-203, 2001.

WALSH, M.J.; FRIESEN, S.; POWLES, S. Frequency, distribution and mechanisms of herbicide resistance in Western Australian wild radish (Raphanus raphanistrum L.) populations: a review; Fifteenth Australian Weeds Conference, Papers and Proceedings, Western Australia, 2006, p.484-487.

YU, Q. et al. ALS gene proline (197) mutations confer ALS herbicide resistance in eight separated wild radish (Raphanus raphanistrum) populations. Weed Science, v.51, n.6, p.831-838, 2003.

YU, Q. et al. Resistance evaluation for herbicide resistance-endowing acetolactate synthase (ALS) gene mutations using Raphanus raphanistrum populations homozygous for specific ALS mutations. Weed Research, v.52, n.2, p.178-186, 2012. 